\title{
Testicular ultrasound evaluation in small animal practice
}

\section{[Avaliação ultrassonográfica testicular na clínica de pequenos animais]}

\section{"Revisão/Review"}

\author{
Francisco Felipe de Magalhães $^{1 *}$, Mírley Barbosa de Souza $^{2}$, Lúcia Daniel Machado da Silva ${ }^{1}$ \\ ${ }^{1}$ Laboratório de Reprodução de Carnívoros, Programa de Pós-Graduação em Ciências Veterinárias, Universidade \\ Estadual do Ceará, Fortaleza-CE, Brasil. \\ ${ }^{2}$ Laboratório de Diagnóstico por Imagem Aplicado a Reprodução, Programa de Pós-Graduação em Ciências Veterinárias, \\ Universidade Estadual do Ceará, Fortaleza-CE, Brasil. \\ *Autor para correspondência/Corresponding author: E-mail: felipefavet@gmail.com
}

\begin{abstract}
Ultrasonographic imaging allows a detailed evaluation of the testicles of dogs and cats. It has been used as a tool for reproductive evaluation as well as for the detection of conditions that can affect the gonads. B-mode ultrasound evaluates the echogenicity, echotexture, and testicular volume parameters and, using the Doppler tool, the vascularization is evaluated at that location. Contrast-enhanced ultrasound provides information about the microvasculature, which may suggest a possible vascular impairment affecting fertility. Although most testicular pathologies can be detected by these techniques, there are still concerns about the differential diagnosis and better understanding of the ultrasound imaging resulting from these conditions. Due to the great importance of this tool, this study aims to conduct a review on the use of testicular ultrasound of dogs and cats, exploring the normal and abnormal characteristics observed in each exam and the perspective on the use of contrast agents in the evaluation of gonads of these animals.
\end{abstract}

Keywords: gonads; ultrasound; breeding soundness evaluation.

\section{Resumo}

A ultrassonografia permite uma avaliação detalhada dos testículos de cães e gatos. Ela tem sido utilizada como ferramenta para avaliação reprodutiva, bem como para detecção de afecções que podem acometer as gônadas. Por meio da ultrassonografia em modo bidimensional avaliam-se os parâmetros de ecogenicidade, ecotextura e volume testicular e por meio da ferramenta Doppler, avalia-se a vascularização naquele local. Já ultrassonografia contrastada fornece informações acerca da microvasculatura, podendo desta forma sugerir um possível comprometimento vascular afetando a fertilidade. Embora a maioria das patologias testiculares possa ser detectada por essas técnicas, ainda há preocupações sobre o diagnóstico diferencial e melhor compreensão das imagens ultrassonográficas resultantes destas afecções. Devido à grande importância desta ferramenta, este estudo tem como objetivo realizar uma revisão de literatura sobre o uso de ultrassonografia testicular de cães e gatos, explorando as características normais e anormais observadas em cada exame e a perspectiva no uso de agentes de contraste na avaliação de gônadas desses animais.

Palavras-chave: gônadas; ecografia; avaliação andrológica.

\section{Introdução}

Ultrasound examination of the testes has been used for several years to improve the evaluation of reproductive status, as well as to detect abnormalities in the structure and perfusion of these organs, being essential for breeding soundness examination, as some testicular disorders produce tissue damage which in some

cases can be diagnosed by means of the physical examination only in advanced stages (Feliciano et al., 2013; Souza et al., 2015). This technique has the advantage of not being invasive, allowing the evaluation of the dynamic function, and usually not requiring general anesthesia or sedation (Kealy et al., 2011). 
B-mode ultrasound allows the evaluation of the size, location, parenchymal appearance, and testicular volume measurements, in addition to diagnosing changes in these parameters (Domingos and Solomão, 2011). Doppler ultrasonography is used to determine the presence of blood flow, its direction, and to detect velocity abnormalities (Souza et al., 2014). The use of Doppler ultrasonography to evaluate the perfusion of the testicles in dogs (Zelli et al., 2013) and cats (Brito et al., 2015) has already been described.

The use of contrast-enhanced ultrasound for evaluation of the reproductive system is a relatively new modality in dogs and cats, allowing a more detailed examination of the microvasculature, providing an amplified image of the vascularization of organs studied with the aid of contrast-enhanced agents injected before the examination (Volta et al., 2014), and it is possible to help in the identification of modifications caused by inflammatory and/or neoplastic processes not detected by Doppler ultrasound scans (Bigliardi and Ferrari, 2011).

Due to its importance to improve the breeding soundness evaluation, this study aimed to conduct a review on the description of normal appearance of canine and feline testes by B-mode ultrasound and Doppler, as well as the description of the abnormalities detected by these ultrasound modalities. Finally, the use of contrasted-enhanced ultrasound of the testes will be addressed, mentioning the possibility of this technique to diagnose abnormalities with greater precision.

\section{B-mode ultrasound of normal testes and epididymis}

In dogs, the normal testes have medium echogenicity and homogeneous echotexture with stippled appearance (Souza et al., 2017). The parietal and visceral tunics appear as a hyperechoic peripheral echogenic capsule. The mediastinum appears in the longitudinal plane as a hyperechoic central line and in the transverse plane, appears as an echogenic spot (Figure 1). In prepubescent dogs, the echogenicity of the testis is more hypoechoic than in adult dogs and the mediastinum can be easily identified (Souza et al., 2017). In older dogs, small hyperechoic foci representing the testicular septa are occasionally visualized (Penninck and D'anjou, 2015).

According to Davidson and Tomas (2009), the ultrasound examination of the testicles of domestic felines was useful for evaluation of normal morphology, volume measurements and testicular diameter, as well as the detection of dystrophies and anomalies of the testicular stroma and adjacent structures present in the scrotum.

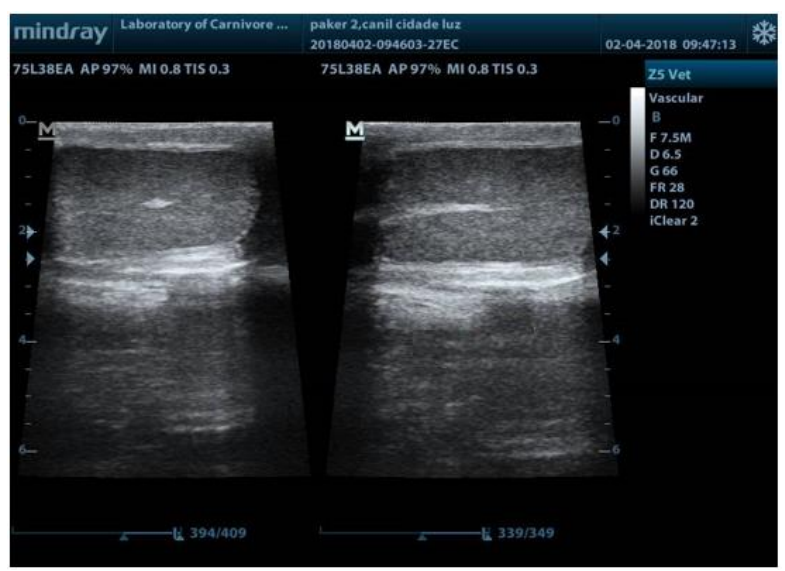

Figure 1. B-mode ultrasonography of dog testis. (Left side) In the transverse plane, the mediastinum appears as an echogenic spot. (Right side) The mediastinum appears in the longitudinal plane as a hyperechoic central line.

Usually, there are no differences in echogenicity between the right and left testicles; however, differences in testicular volume between right and left testis have already been observed in some studies. The testicular volume can be calculated in the formula: volume $=$ length $\mathrm{x}$ width $\mathrm{x}$ height $\mathrm{x}$ 0.5236. A number of studies have demonstrated a positive association between testicular volume and canine body weight (Souza et al., 2017).

In clinical practice, ultrasound images are subjectively assessed and described in terms of their texture; mainly echogenicity and heterogeneity. A small number of studies have proposed a relationship between grossly detectable lesions within the testes and semen quality (Vencato et al., 2014).

Objective analysis of echogenicity from measurements of pixel intensity is possible using digital image analysis (Ivancic and Mai, 2008). This allows measurement of the characteristics of the tissue (Cardilli et al., 2010) and enables detection of changes in echogenicity which may not be detected by the human eye (Moxon et al., 2015).

Quantitative ultrasound measurement of ultrasonographic homogeneity/heterogeneity has also been previously assessed by calculation of the standard deviation of pixel intensity (Hershkovitz et al., 2010). For testes, ultrasound pixel heterogeneity has been directly correlated with 
tissue biochemical composition (Omer et al., 2012; Ahmadi et al., 2013). There are, however, only a few reports demonstrating a relationship between quantitative measurement of either testes echogenicity or heterogeneity and semen quality (Ahmadi et al., 2012). Kastelic and Brito (2012) proposed that the primary clinical use of ultrasonography was for grossly detectable lesions since quantitative pixel analysis was not predictive of semen quality in bulls.

In adult cats, testes are easily located by ultrasonography within the scrotum, showing echotexture and echogenicity similar to the spleen, in addition to the central hyperechoic line that corresponds to the mediastinum in the longitudinal plane and as a central spot in the transverse plane (Davidson and Tomas, 2009).

The epididymis can be identified as a moderately hypoechogenic circular structure and coarse echotexture (relative to the testicular parenchyma), positioning itself along the dorsolateral surface of the testis (Penninck and D'anjou, 2015; Souza et al., 2017). The tail of the epididymis can be seen in the dorsal image in the caudal plane of the testis, being less echogenic than the testicular parenchyma. Measurements of the epididymal diameter for different breeds vary from 0.6 to $1.3 \mathrm{~cm}$ (mean of $0.88 \mathrm{~cm}$ for the tail, 0.4 to $0.8 \mathrm{~cm}$ for the head, and 0.2 for $0.7 \mathrm{~cm}$ for the body (Hecht., 2015).

The spermatic cord can be visualized from the head of the epididymis to the inguinal ring, characterized by large tortuous and anechogenic venous structures of the pampiniform plexus. This plexus is represented by a prominent and complex pattern flow on color Doppler (Meyers-Wallen, 2008).

\section{Testicular abnormalities \\ B-mode ultrasound}

Ultrasound scans of the testes and the scrotum is used to evaluate palpable and nonpalpable changes to differentiate testicular and epididymal changes from scrotal abnormalities and to enable the localization of ectopic testes that remain in the abdominal cavity or inguinal region (Hecht., 2015).

Testicular disorders include cryptorchidism, testicular neoplasm, orchitis, epididymitis, testicular or epididymal cysts, testicular torsion, infarction, atrophy and trauma. Other pathological disorders affecting the scrotum include the accumulation of fluid (hydrocele) or blood (hematocele) and scrotal hernia. The accuracy in diagnosing testicular and / or scrotal disorders in dogs is high (Souza et al., 2017).

Cryptorchidism is a condition of congenital origin identified in dogs and cats, characterized by failure of one or both testicles to descend to the scrotum until 1 year of age, which is the usual time for inguinal ring closure. It is more commonly diagnosed in dogs compared to cats; can be uni or bilateral, and the position of the ectopic testis may be pre-scrotal, inguinal or abdominal (Felumlee et al., 2012). It can be found anywhere along the course between the caudal pole of the kidneys to the bladder, mainly adjacent to the bladder, but can also be detected in the subcutaneous tissue, adjacent to the hypogastric fatty tissue, or between the foreskin and the scrotum.

Cryptorchid testes are normally small, rounded, with regular contours, hypoechoic with fine echotexture (in relation to the surrounding tissue), and have normal architecture with a hyperechoic central mediastinum. If the mediastinum is not developed, identification of a testis that has not descended can be difficult. Occasionally, the gubernacus is visualized, appearing as a tubular structure that extends from the caudal pole of the testicle to the inguinal ring. Testes located in the abdomen or inguinal canal are predisposed to neoplastic transformation, presenting irregular contour, mixed echogenicity and coarse echotexture, being able to reach considerable sizes in these cases (Feliciano et al., 2013; Penninck and D'anjou, 2015).

Orchitis has variable sonographic aspects, ranging from irregular anechoic to focal or diffuse hypoechoic areas. In general, the testes have irregular architecture, with irregular contour and inflamed areas characterized by more hypoechogenic images in relation to the normal testicular parenchyma. There may be areas with abscess formation in the parenchyma or epididymis, seen as anechoic or hyperechoic areas filled with anechoic content. In chronic cases, hyperechoic spots that result in the formation of acoustic shadow can be seen from fibrosis or mineralization in the testicular interstice (Souza et al., 2017).

Ultrasonographic findings in testicular tumors vary according to evolution and type of tumor, ranging from small circumscribed nodules to large complex masses with disruption of normal testis anatomy. In the initial phase of the disease, there is a testicular parenchyma with homogeneous 
or discrete heterogeneous echotexture, a discrete alteration of parenchymal echogenicity, presence of nodules with irregular contour, heterogeneous coarse echotexture, hypoechoic and anechoic areas, and may present a hyperechoic margin (Feliciano et al., 2013).

With development of a tumor, the affected testis presents irregular contours, coarse echotexture of heterogeneous aspect, abnormal echogenicity and dimensions, cavitary lesions, focal or diffuse areas, which can be anechoic or hypoechoic, representing hemorrhagic necrosis and hyperechoic areas representing mineralization that may result in discrete acoustic shadow. The tumor type differentiation cannot be made by ultrasonographic examination and confirmation of the diagnosis should be made through fine needle aspiration cytology or testicular biopsy for histopathological analysis (Souza et al., 2017).

Testicular or epididymal cysts are incidental findings. They appear as anechoic areas, well circumscribed, rounded and often presenting posterior acoustic reinforcement (Penninck and D'anjou, 2015).

Testicular torsion is an acute alteration that occurs more frequently in the cryptorchid testicle affected by a neoplastic process, retained in the abdominal cavity, however, it can affect testicles located in the scrotum, which may be normal or abnormal. During ultrasound examination, intraabdominal testicular torsion is identified by structure, size and variable echogenicity, with reduced flow or absent color Doppler (Viliotti et al., 2018).

When located in the scrotum, the affected testis is seen with increased dimensions, reduced echogenicity, dilatation of the epididymis and spermatic cord, scrotal thickening and loss of vascularization at Doppler examination. Depending on the degree and duration of vascular occlusion, the testis may appear hyperechoic or hypoechoic, normal or decreased with normal initial architecture. Concomitant scrotal or abdominal effusion is common, especially in acute cases (Souza et al., 2017).

Testicular atrophy can have several causes such as thermal injury, anterior orchitis, hormonal influences, or vascular impairment. The atrophic testes are small and hypoechoic, but maintain their normal architecture (Christensen, 2012).

Scrotal hernias occur when defects of the inguinal ring allow the abdominal contents to protrude from the interior of the vaginal process adjacent to the spermatic cord. Congenital defects or trauma may predispose the occurrence of scrotal hernia, that in most cases are unilateral and described more frequently in chondrodistrophic animals. Ultrasonographic findings include hydrocele and testicular congestion or infarction, as well as intestinal loops or mesenteric fat (Penninck and D'anjou, 2015).

Varicocele occurs more frequently in elderly dogs and is characterized by the formation of varicose veins in the region of the scrotum. Ultrasound imaging shows vascular dilatation (Feliciano et al., 2013).

In dogs, the development of ultrasound techniques to access reproductive organs and auxiliary tools for the diagnosis of diseases are well described in the veterinary literature. However, in cats, ultrasonography is less described as a diagnosis method due to the rare condition of some reproductive changes. Some reports describe the occurrence of prostatic diseases, such as neoplasms, para-prostatic cysts and prostatitis (Pointer and Murray, 2011).

Testicular neoplasms are also rare in cats, as well as in dogs, and can be diagnosed by ultrasonography. There are few reports in the literature on the occurrence of Leydig cell tumors, interstitial cells and Sertoli cells, the latter being the most recurrent, especially in cases of cryptorchidism (Asproni et al., 2013; Tucker and Smith, 2008).

\section{Doppler ultrasound}

Among the recent advances in the technology of ultrasound equipment, one of them has taken center stage in the evaluation of the function of several organs. Doppler mode is a technique that has helped elucidate in real time the irrigation characteristics of parenchymal organs such as testicular tissue (Carrillo et al., 2012).

A number of studies on the use of Doppler have been performed in dogs (Zelli et al., 2013; Souza et al., 2014; Moxon et al., 2015) and cats (Brito et al., 2015). This evaluation is used to verify testicular perfusion and, therefore, it helps in the diagnosis of diseases related to testicular vascularization (Dudea et al., 2011).

The testes and the epididymis receive their blood supply via the testicular artery. The arterial segment within the spermatic cord has a thick wall and a small lumen, this region being called the supratesticular artery. The testicular artery that emerges from the spermatic cord has a thinner wall 
and larger lumen, and extends through the epididymal margin of the testicles, near the capsule, usually performing a linear course without any branch, which is called the marginal artery. The terminal segment that penetrates the testicular parenchyma (intratesticular arteries) are directed to the mediastinum (Souza et al., 2017).

Doppler ultrasound of the testicular artery and its branches in different kinds of species begins with the evaluation in B-mode and its later association with the detection of the vascular beds by color and pulsed-wave Doppler ultrasound. Through this evaluation, vascular parameters that characterize the flow of the testicular artery can be determined, as well as a comparison with the branches of the artery (Souza et al., 2014).

The Doppler parameters investigated are: peak systolic velocity (PSV); end diastolic velocity $(\mathrm{EDV})$; the vascular resistance $(\mathrm{RI}=\mathrm{Vmax}-\mathrm{Vmin}$ / Vmax); and pulsatility (PI = Vmax - Vmin / Vmean) indexes. These parameters must be obtained under conditions of angulation between the ultrasound beam and the vascular flow and with adequacy of the caliper to the vessel diameter, in order to allow the Doppler sample contemplating a central region of the vessel, avoiding the turbulence of the vascular borders. Three similar spectrums must be taken into consideration for the acquisition of a mean that characterizes the blood flow of the vessel (Carvalho et al., 2008).

Zelli et al. (2013), studying the evaluation of testicular artery blood flow by Doppler ultrasonography as a predictor of spermatogenesis in the dog, quoted that blood flow velocities represent an angle-dependent technique, and that careful interpretation is required with such techniques. This crucial ultrasound limitation factor is absent when using the indices (RI and PI) to assess blood flow, as they are independent of the angle. Resistive Index is a measure of blood flow that reflects the resistance to blood flow caused by the microvascular bed distal to the site of measurement while PI is designed to quantify the pulsatility or oscillations of the waveform. The RI and PI are widely used to study testicular blood flow perfusion in animals in physiological (Carrillo et al., 2012) and pathological conditions (Dudea et al., 2011).

Normal blood flow of the testicular artery may change depending on the region evaluated when submitted to ultrasound in pulsed-wave Doppler ultrasound. In the supratesticular region, two patterns of waveforms can be visualized due to the tortuous feature of the artery in this region: first, a biphasic waveform, with a diastolic notch followed by a diastolic peak; second, a singlephase waveform characterized by a systolic peak followed by a decrease in diastolic flow. The marginal and intratesticular regions of the artery have a low resistance flow with monophasic waves, normally seen arteries that irrigate parenchymal structures. Doppler velocimetric parameters showed differences according to the artery region measured, as well as the Doppler ultrasound waveforms (Figures 2, 3 and 4). High velocities are present within the supratesticular region, which decrease along the marginal and intratesticular regions. Moreover, these parameters are different in dogs of different sizes (Souza et al., 2014) and in pre and postpubertal dogs (Souza et al., 2015).

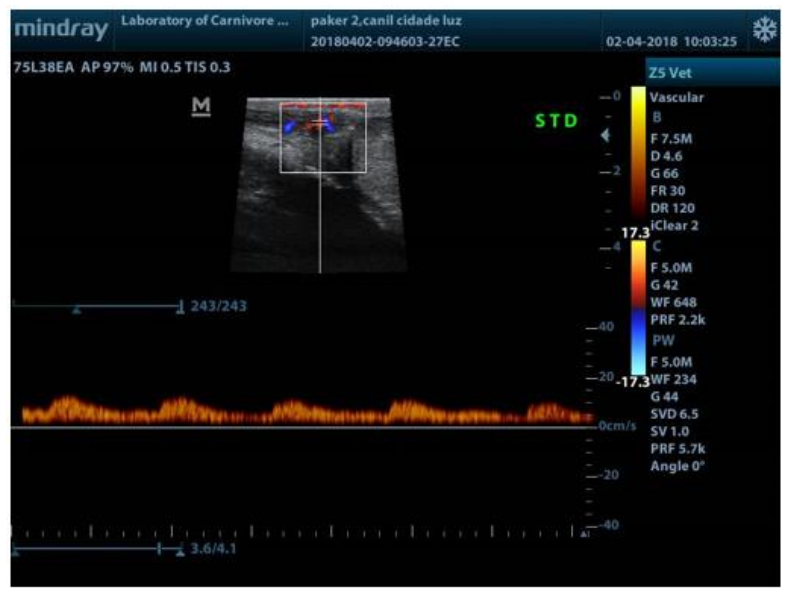

Figure 2. Typical Doppler ultrasound waveforms from the supratesticular artery of an adult dog.

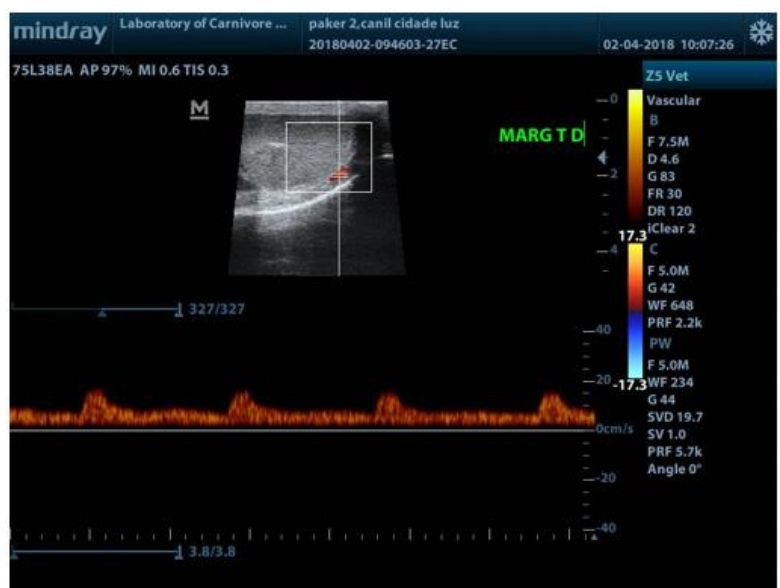

Figure 3. Typical Doppler ultrasound waveforms from the marginal artery of an adult dog.

Brito et al. (2015), evaluating adult domestic cat testes using Doppler ultrasound, observed that using color Doppler, the detection of feline testicular artery was consistent, identified dorsally, between testicular and epididymal structures and 
with tortuous pattern, as described in the literature in canines (Carrillo et al., 2012; De Souza et al., 2014).

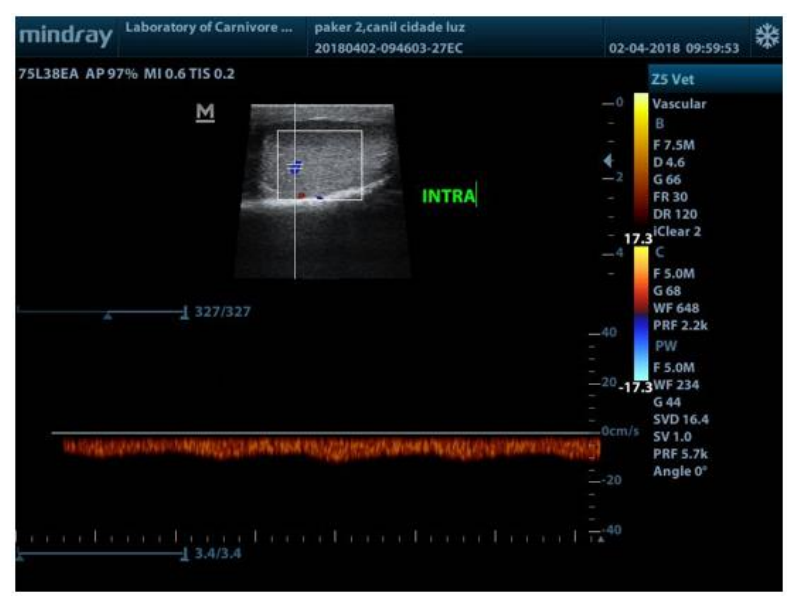

Figure 4. Typical Doppler ultrasound waveforms from the intratesticular artery of an adult dog.

The identification of marginal and intratesticular portions of the testicular artery in cats was limited, probably due to the small testicular volume, compared with dogs. During the spectral Doppler exam, the testicular arteries of cats exhibited a pattern similar to that described in dogs (Carrillo et al., 2012; Souza et al., 2014). According to Carvalho et al. (2008), the testicular artery showed characteristic waves of low resistivity, with low pulsatility and resistance, featuring flows with large and continuous systolic peaks and high speed flow during diastole, typical of organs with continuous demand of blood. Regarding the vascular indices of the testicular artery in cats, the values for systolic (SV: $21.06 \pm$ $1.3 \mathrm{~cm} / \mathrm{s}$ ) and diastolic velocities (DV: $4.85 \pm 0.44$ $\mathrm{cm} / \mathrm{s}$ ) are lower than those observed in dogs (Carrillo et al., 2012; Souza et al., 2014; Souza et al., 2015), justified by the smaller testicular structures, which require less blood supply than the canine testicular tissue. However, the RI of assessed vessels is similar to dogs (Carrillo et al., 2012; Souza et al., 2014; Souza et al., 2015), as this feature depends on other factors such as vessel diameter and blood flow region, with no influence of tissue size.

\section{Contrast-enhanced ultrasound}

Contrast-enhannced ultrasound is a diagnostic tool in research and routine of Veterinary Medicine, making the realization of the diagnoses safer and more sophisticated, regarding changes in several organs that are affected by affections with consequences in the vascular perfusion, as is the case of neoplasias (Volta et al., 2014). It offers advantages over Doppler ultrasonography since the branches of the testicular artery and the perfusion of the parenchyma are readily observed and can be measured using quantitative methods (Souza et al., 2017).

The main contrast agent used is sulfur hexafluoride, a contrast agent able to remain stable within the blood circulation, without leaving the vascular bed, besides being able to maintain a long period in the circulation due to its low solubility in water and gaseous molecules of high molecular weight, having great resistance to external pressure and excellent tolerance to the animal organism (Volta et al., 2014). It has a low ability to promote adverse reactions, with reported reactions in animals such as syncope and vomiting up to 24 hours after administration (Seiler et al., 2013).

The physical principle of the detection of microbubbles is the detection of the nonlinear signal produced by bubbles of different sizes present in fractions of blood that, when coming into contact with the ultrasound beam, generate socalled harmonic frequencies. The large amount and oscillation of the microbubbles in a certain region of ultrasound scan generates a strong contrast in the surface of the organ under study when visualized in the equipment screen, thus allowing the detection of microvascularizations that were previously not noticed, even using Power Doppler (Volta et al., 2014).

This evaluation defines parameters related to the homogeneous or heterogeneous filling of the organs by the microbubbles, but mainly of specific nodular areas inside the tissues, being able to define patterns of intensity: more intense "hyperenhanced"; "isoenhanced", where the mass of adjacent tissue is not differentiated using contrast; and with a low intensity pattern hypoenhanced (Volta et al., 2014).

In addition, evaluations using contrastenhanced ultrasound can provide: time of vascular filling from the injection of contrasts in the bloodstream to the beginning of the perfusion ("wash in"); the contrast peak (enhancement), which is the moment of greater perfusion after the "wash in"; and total parenchyma exit time ("wash out"). This pattern of microvascular filling has substantial value for the early determination of small masses in the early stages of evolution and hypervascularization in aggressive tumors, and may aid in the differentiation between malignant 
and benign tumors in a noninvasive way (Lock et al., 2009).

After injection of the contrast agent, the tortuous supratesticular arteries become opaque, followed by the clear enhancement of the marginal arteries and finally the intratesticular arteries, with the flow toward the mediastinum. The testicular parenchyma increases echogenicity during the vascular bed phase and then the contrast agent is gradually cleared from the parenchyma during the wash out phase (Souza et al., 2017). The testicular veins are prominent and less echogenic compared to the arteries, with a greater persistence of contrast within their vascular bed, resulting in a longer time of total parenchymal contrast output (Souza et al., 2017).

Reliable data for the use of contrastenhanced ultrasonography in normal dogs using standard protocols for contrast agent administration has been described (Volta et al., 2014). However, the limitations include the high costs of contrast agents and the need for specialized ultrasound equipment. Quantitative measurements for normal testis in anesthetized dogs show a wash in phase of approximately 27 seconds, peak perfusion intensity mean of $16.6 \%$, time to reach peak intensity of 35 seconds, and a 40 second wash out phase. Additional studies are needed to document variations in perfusion kinetics and to establish faster protocols that can be applied to conscious dogs (Souza et al., 2017).

Studies using the same technique in cats showed that the testicular artery in the spermatic cord (homogeneously) was rapidly filled by contrast agent. The contrast filled subcapsular vascular structures and, after a few seconds, a moderate homogeneous parenchymal increase was observed, with parenchymal vessels still distinguishable. After the peak phase, a rapid homogeneous drop in echogenicity was detected. After approximately 90 seconds, few microbubbles were visible in the testicular parenchyma (Brito et al., 2015).

\section{Acoustic radiation force impulse (ARFI) elastography of the testes}

Acoustic radiation force impulse (ARFI) elastography is an ultrasonographic technique that provides quantitative and qualitative measurements of tissue stiffness, with reduced inter-observer variability (Feliciano et al., 2015). Qualitative ARFI creates a static greyscale map (elastogram) that represents the relative stiffness of the tissue in the scanned area and which can be compared to a corresponding conventional ultrasound scan. In general, lighter areas represent more pliable tissue than darker areas (D'Anastasi et al., 2011; Goddi et al., 2012).

Quantitative ARFI creates propagating pressure waves that are capable of deforming the tissue quantitatively (pressure wave velocity of propagation or shear velocity). The velocity of propagation and attenuation of the waves are related to the stiffness and viscoelasticity of the tissue (Comstock, 2011; Dudea et al., 2011).

Studies have demonstrated that elastography can provide auxiliary and important information in the evaluation of testicular lesions, both for detection of small lesions and for differentiation of benign and malignant disorders (Aigner et al., 2012; Goddi et al., 2012; Huang and Sidhu, 2012).

In Veterinary Medicine, Feliciano et al. (2015) conducted the first study on the use of the ARFI technique in the evaluation and standardization of reference values for canine testicles and obtained important results on the qualitative and quantitative analysis of healthy tissues in animals from different age groups. Futhermore, analysis of the stiffness of canine testicular tissue by ARFI elastography provides a noninvasive alternative in the diagnosis of testicular alterations in small animals.

However, there are few studies on the use of this technique in the evaluation of testicular diseases in animals, where qualitative elastography showed that healthy testicular parenchyma was homogenous (midgray) and not pliable. On the other hand, abnormal testicles were stiff and not homogeneous. For quantitative elastography, the mean shear velocity value of normal healthy testicles was $1.30 \pm 0.12 \mathrm{~m} / \mathrm{s}$. The results obtained for stiffness of the analyzed tissues are promising and can help in the diagnosis of the main testicular diseases in dogs, as well as in humans (Feliciano et al, 2016).

\section{Final considerations}

There is no doubt that advanced ultrasound techniques are now becoming more common as diagnostic tools for the investigation of canine and feline testicular changes. Although B-mode testicular image of domestic canines and felines has been performed clinically for more than 30 years, there has been a substantial improvement in ultrasound equipment technology, and recent studies on arterial blood flow and vascularization 
using the Doppler technique and contrast-enhanced ultrasound have provided greater and valuable information on the subject.

\section{Conflict of Interest}

The authors declare no conflict of interest.

\section{References}

Ahmadi, B.; Lau, C.P.; Giffin, J.; Santos, N.; Hahnel, A.; Raesside, J.; Christie,H.; Bartlewski, P. Suitability of epididymal and testicular ultrasonography and computerized image analysis for assessment of current and future semen quality in the ram. Experimental Biology and Medicine, 237(2): 186-193, 2012.

Ahmadi, B.; Mirshahi, A.; Giffin, J.; Oliveira, M.E.; Gao, L.; Hahnel, B.; Bartlewski, P. Preliminary assessment of the quantitative relationships between testicular tissue composition and ultrasonographic image attributes in the ram. The Veterinary Journal, 198(1): 282-285, 2013

Aigner, F.; De Zordo, T.; Pallwein-Prettner, L.; Junker, D.; Schäfer, G.; Pichler, R.; Leonhartsberger, N.; Pinggera, G.; Dogra, V.S.; Frauscher, F. Real-time Sonoelastography for the evaluation of testicular lesions. Radiology, 263(2): 584589, 2012.

Asproni, P.; Millanta, F.; Lorenzi, D.; Poli, A. A Leydig Cell Tumour in a cat: histological and immunohistochemical findings. Case Reports in Veterinary Medicine, 2013:1-3, 2013.

Bigliardi, E.; Ferrari, L. Contrast-enhanced ultrasound of the normal canine prostate gland. Veterinary Radiology \& Ultrasound, 52(1): 107-110, 2011.

Brito, M.; Feliciano, M.; Coutinho L.N.; Uscategui, R.R.; Simões, A.; Maronezi, M.C.; Almeida, V.T.; Crivelaro, R.M.; Gasser, B.; Pavan, L.; Russiano, W.R. Doppler and contrast-enhanced ultrasonography of testicles in adult domestic felines. Reproduction in Domestic Animals, 50(5): 730-734, 2015.

Cardilli, D.J.; Toniollo, G.H.; Pastore, A.A.; Canola, J.C.; Mercadante, M.E.Z.; Oliveira, J.A. Padrão ultrassonográfico do parênquima, mediastino, e túnicas testiculares em bovinos jovens da raça Nelore. Ciência Animal Brasileira, 11(4): 899-905, 2010.
Carrillo, J.D.; Soler, M.; Lucas, X.; Agut, A. Colour and pulsed doppler ultrasonographic study of the canine testis. Reproduction in Domestic Animals, 47(4): 655-659, 2012.

Carvalho, C.F.; Chammas, M.C.; Cerri, G.G. Princípios físicos do Doppler em ultrassonografia. Ciência Rural, 38(3): 872$879,2008$.

Christensen B.W. Disorders of sexual development in dogs and cats. Veterinary Clinics of North America: Small Animal Practice, 42(3): 515-526, 2012.

Comstock, C. Ultrasound elastography of breast lesions. Ultrasound Clinics, 6: 407-415, 2011.

D'Anastasi, M.; Schneevoigt, B.S.; Trottmann, M.; Crispin, A.; Stief, C.; Reiser, M.F.; Clevert, D.A. Acoustic radiation force impulse imaging of the testes: a preliminary experience. Clinical Hemorheology and Microcirculation, 49(1-4): 105-114, 2011.

Davidson, A.P.; Tomas, W.B. Reproductive ultrasound of the dog and tom. Topics in Companion Animal Medicine, 24(2): 64-70, 2009.

Domingos, T.C.S.; Salomão, M.C. Meios de diagnóstico das principais afecções testiculares em cães: revisão de literatura. Revista Brasileira de Reprodução Animal, 35(4): 393-399, 2011.

Dudea, S.M.; Giurgiu, C.R.; Dumitriu, D.; Chiorean, A.; Ciurea, A.; Botar-Jid, C.; Coman, I. Value of ultrasound elastography in the diagnosis and management of prostate carcinoma.

Medical Ultrassonography,13(1): 45-53, 2011.

Feliciano, M.A.R.; Oliveira, M.E.F.; Vicente, W.R.R. Ultrassonografia na reprodução animal. $1^{\text {a }}$ ed. São Paulo: MedVet, 2013. 191 p.

Feliciano, M.A.R.; Maronezi, M.C.; Simões, A.P.R.; Uscategui, R.R.; Maciel, G.S.; Carvalho, C.F.; Canola, J.C.; Vicente, W.R.R. Acoustic radiation force impulse elastography of the prostate and testes of dogs: initial results. Journal of Small Animal Practice, 56(5): 320-324, 2015.

Feliciano, M.A.R.; Maronezi, M.C.; Simões, A.P.R.; Maciel, G.S.; Pavan, L.; Gasser, B.; Silva, P.; Uscategui, R.R.; Carvalho, C.F.; Canola, J.C.; Vicente, W.R.R. Acoustic radiation force impulse (ARFI) elastography of testicular disorders in dogs: preliminary 
results. Arquivo Brasileiro de Medicina Veterinária e Zootecnia, 68(2): .283-291, 2016.

Felumlee, A.E.; Reichle, J.K.; Hecht S.; Penninck, D.; Zekas, L.; Dietze Yeager, A.; Goggin, J. M.; Lowry, J. Use of ultrasound to locate retained testes in dogs and cats. Veterinary Radiology \& Ultrasound, 53(5): 581-585, 2012.

Goddi, A.; Bonardi, M.; Alessi, S. Breast elastography: a literature review. Journal of Ultrasound, 15(3): 192-198, 2012.

Hecht, S. Male reproductive tract. In: Penninck, D.; Anjou, M.A. (Eds.). Atlas of small animal ultrasonography. Iowa: Wiley Blackwell, 2015. p. 417-444.

Hershkovitz, R.; Amichay, K.; Stein, G.Y.; Tepper, $R$. The echogenicity of the normal fetal kidneys during different stages of pregnancy determined objectively. Archives of Gynecology and Obstetrics, 284(4):807-811, 2010.

Huang, D.Y.; Sidhu, P.S. Focal testicular lesions: colour doppler ultrasound, contrast-enhanced ultrasound and tissue elastography as adjuvants to the diagnosis. The British Journal of Radiology, 85(2012): 41-53, 2012.

Ivancic, M.; Mai, W. Qualitative and quantitative comparison of renal vs. hepatic ultrasonographic intensity in healthy dogs. Veterinary Radiology and Ultrasound, 49(4): 368-373, 2008.

Kastelic, J.P.; Brito, L.F. Ultrasonography for monitoring reproductive function in the bull. Reproduction in Domestic Animals, 47(3): 45-51, 2012.

Kealy, J.K.; McAllister, I.; Graham, J.P. Diagnostic radiology and ultrasound of the dog and cat. $5^{\text {th }}$ ed. St Louis: Saunders, 2011, 592p.

Lock, G.; Schmidt, C.; Helmich, F.; Stolle, E.; Dieckmann, K.P. Early experience with contrast-enhanced ultrasound in the diagnosis of testicular masses: a feasibility study. Urology, 77(5): 1049-1053, 2009.

Meyers-Wallen, V.N. Inherited disorders of the reproductive tract in dogs and cats. In: Bonagura, J.D; Twedt, D. C. Kirk's current veterinary therapy XV. Philadelphia: WB Saunders, 2008. p. 244-250.

Moxon, R.; Bright, L.; Pritchard, B.; Mark Bowen, I.; Souza, M.B.; Silva, L.D.; England, G.C.W.
Digital image analysis of testicular and prostaticultrasonographic echogencity and heterogeneity in dogs and the relation to sêmen quality. Animal Reproduction Science, 160: 112-119, 2015.

Omer, R.; Giffin, J.; Hahnel, A.; Bartlewski, P. Relationships of ultrasonographic and magnetic resonance image attributes to the histomorphology of ram testes. Reproductive Biology, 12(4): 355-361, 2012.

Penninck, D.; D'Anjou., M.A. Male reproductive tract. In:__. Atlas of small animals ultrasonography. Iowa: Wiley Blackwell, 2015. 27p.

Pointer, E.; Murray, L. Chronic prostatitis, cystitis, pyelonephritis, and balanoposthitis in a cat. Journal of the American Animal Hospital Association, 47(4): 258-261, 2011.

Seiler, G.S.; Brown, J.C.; Reetz, J.A.; Taeymans, O.; Bucknoff, M.; Rossi, F. Safety of contrastenhanced ultrasonography in dogs and cats: 488 cases (2002-2011). Journal of American Veterinary Medical Association, 242(9): 1255-1259, 2013.

Souza, M. B.; Mota Filho, A.C.; Sousa, C.V.S.; Monteiro, C.L.B.; Carvalho, G.G.; Pinto, J.N. Triplex Doppler evaluation of the testes in dogs of different sizes. Pesquisa Veterinária Brasileira, 34(11): 1135-1140, 2014.

Souza, M.B.; Barbosa, C.C.; England, G.C.; Mota Filho, A.C.; Sousa, C.V.; Carvalho, G.G. Regional differences of testicular artery blood flow in post pubertal and pre-pubertal dogs. BMC Veterinary Research, 11(47): 1-6, 2015.

Souza, M.B.; Silva, L.D.M.; Moxon, R.; Russo, M.; England, G.C.W. Ultrasonography of the prostate gland and testes in dogs. In Practice, 39(1): 21-32, 2017.

Tucker, A.; Smith, J. Prostatic squamous metaplasia in a cat with interstitial cell neoplasia in a retained testis. Veterinary Pathology, 45(6): 905-909, 2008.

Vencato, J.; Romagnoli, S.; Stelletta, C. Transscrotal ultrasonography and testicular fineneedle aspiration cytology in the evaluation of ram sperm production. Small Ruminant Research, 120: 112-115, 2014.

Viliotti, T.A.A.; Ferraz, R.E.O.; Lucena, L.V.; Monteiro, C.L.B.; Mota-Filho, A.C. Torção testicular em saco escrotal de canino jovem. Acta Scientiae Veterinariae, 46(1): 1-6, 2018. 
Volta, A.; Manfredi, S.; Vignoli, M.; Russo, M.; England, G.; Rossi, F. Use of ContrastEnhanced Ultrasonography in Chronic Pathologic Canine Testes. Reproduction in Domestic Animals, 49(2): 202-209, 2014.
Zelli, R.; Troisi, A.; Elad Ngnonput, A.; Cardinali, L.; Polisca, A. Evaluation of testicular artery blood flow by Doppler ultrasonography as a predictor of spermatogenesis in the dog. Research in Veterinary Science, 95(2): 632637, 2013. 